\title{
Do mito do centro mediado ao mito do Big Data: reflexões sobre 0 papel da mídia na ordem social ${ }^{1}$ From the myth of the mediated centre to the myth of Big Data: reflections on media's role in social order
}

Nick Couldry ${ }^{2}$

Resumo: O presente artigo investiga a natureza da ordem social e o papel característico das instituições midiáticas na sustentação ou transformação desta ordem. Para tanto, perpassa o meu próprio trabalho, com o objetivo de trazer dimensões ocultas de mudança social que me auxiliaram na compreensão da ordem social em sociedades dataficadas. Discorro sobre minha produção, pontuando o caminho teórico que percorro quanto às novas relações sociais estabelecidas em uma ordem dataficada, de maneira a investigar o funcionamento atual do poder midiático. Para tanto, aloco como parte fundamental a televisão, concluindo que, a despeito da nova ordem social, as instituições midiáticas tradicionais sobrevivem e podem constituir elemento-chave para a criticidade necessária em tempos de dados.

Palavras-chave: dataficação; big data; centro mediado; mídia tradicional; processos sociais.

\footnotetext{
Abstract: This paper investigates the nature of the social order and the characteristic role of media institutions in sustaining or transforming this order. To this, I go through my own work, with the goal of bringing hidden dimensions of social change that have helped me understand the social order in datified societies. I discuss about my production, punctuating the theoretical path that I walk

1 O presente artigo foi apresentado no Congresso Televisões organizado pelo PPGCOM da Universidade Federal Fluminense em 16/05/2019.

2 London School of Economics and Political Science (LSE). Londres, Reino Unido. https://orcid.org/0000-0001-8233-3287.E-mail: n.couldry@lse.ac.uk
} 
408 DO MITO DO CENTRO MEDIADO AO MITO DO BIG DATA

in relation to the new social relations established in a datified society, in order to investigate the current functioning of media power. I allocate television as a fundamental part for this understanding, concluding that, despite the new social order, traditional media institutions survive and may constitute a key element for the criticality needed in data times.

Keywords: datification; big data; mediated center; traditional media; social processes. 


\section{Introdução}

Gostaria de falar a vocês hoje sobre uma das questões mais importantes que norteiam o meu trabalho. Como sociólogo da mídia e cientista social, o tópico que inicialmente me fascinou foi o poder da mídia, especificamente, o poder da televisão. Eu já não trabalho mais com televisão enquanto tal, como explicarei mais profundamente a seguir. No entanto, como também explicarei a seguir, meu interesse de pesquisa fundamental se manteve o mesmo: "a natureza da ordem social e o papel característico das instituições midiáticas na sustentação ou transformação da ordem social”. Nessa palestra, eu gostaria de traçar uma linha que vai do meu trabalho inicial com a televisão até o meu trabalho atual sobre dados e dataficação que expõe o que mudou e o que não mudou em relação a essa questão fundamental da ordem social.

Por dataficação, quero me referir à pressão sentida em todos os lugares atualmente, incluindo as empresas de televisão, para converter todos os aspectos da vida em dados, dos quais valores, em especial valores econômicos, podem ser extraídos. Ao fazê-lo, vou falar muito sobre o meu trabalho. Espero que não pareça egoísta. O meu objetivo é exatamente o contrário: ao refletir sobre as mudanças e continuidades do meu próprio pensamento, quero trazer dimensões ocultas de mudança social que me fizeram ver claramente. Tais dimensões são muito importantes na compreensão da ordem social em sociedades dataficadas.

\section{A abordagem do poder da mídia}

Deixe-me começar por como, desde o início da minha carreira de pesquisador, tentei abordar o tópico amplo do poder da mídia. Esse é um trecho do meu primeiro livro, The Place of Media Power (ainda não traduzido para o português), lançado em 2000: "Analisarei o poder da mídia - a concentração massiva de poder simbólico em instituições midiáticas - como o produto complexo da prática de todos os níveis de interação social. [...] O poder da mídia é reproduzido por meio de pequenos detalhes do que os atores sociais (incluindo membros do 
público) fazem e dizem" (COULDRY, 2000, p. 4). Ao falar sobre o poder de maneira distribuída, dispersa, estava claramente relembrando o trabalho de Michel Foucault, mas, também, estava trazendo a Teoria Ator-Rede. Na página seguinte, eu falo da transformação da mídia em "pontos de passagem obrigatória da circulação geral de imagens e discursos" (uma citação dos fundadores da TAR, Michel Callon e Bruno Latour). Sigo explicando como essa transformação surge na sociedade de maneira mais abrangente: "A mídia [...] tem efeitos sociais de larga escala, não apenas porque os mecanismos centralizados de transmissão estão estabelecidos, mas também porque acreditamos na autoridade do discurso da mídia em inúmeros contextos locais, porque acreditamos que os outros acreditarão da mesma maneira, e porque agimos de acordo com essas crenças em inúmeras ocasiões específicas" (COULDRY, 2000, p. 5). Essa ideia ainda está no cerne do meu trabalho: a importância das nossas crenças na mídia enquanto instituição, e a maneira que agimos de acordo com essas crenças.

Minha decisão de pensar na mídia de maneira mais abrangente, em vez de estudar os detalhes de textos midiáticos ou produções midiáticas, foi inspirada em dois livros: Media Events, escrito por Dayan e Katz, que trouxe abordagens antropológicas para a mídia, e a insistência do grande sociólogo colombiano Jesus Martín-Barbero, em seu livro Dos meios às mediações, sobre estudar não somente a mídia, mas também o amplo "campo das mediações", no qual as nossas relações com a mídia se desenrolam. Mas a minha preocupação inicial era com as implicações dessa perspectiva mais ampla de mídia, não para compreender o empoderamento do povo por meio da mídia, mas para compreender novos recursos de poder por meio da mídia. Assim, citei o cientista social italiano Alberto Melucci que argumentou em seu livro Challenging Codes (1996) que "a dominação real é hoje a exclusão do poder de nomear" (1996, p. 182), uma exclusão na qual a mídia está crucialmente envolvida. Sem dúvida alguma ele foi influenciado pelo excelente trabalho de conscientização de Paulo Freire. E, mais uma vez, não há dúvidas 
quando pensamos, por exemplo, no poder de plataformas como o Facebook, que esse princípio ainda é relevante hoje.

$\mathrm{Na}$ verdade, tentei desenvolver naquela ocasião um modelo de cinco níveis de como o poder da mídia na verdade funciona no mundo social nas práticas do dia a dia. Então, no Capítulo 3, de The Place of Media Power, eu descrevo cinco dimensões subjacentes do poder midiático: o enquadramento (de coisas, lugares e pessoas enquanto especiais); a ordem (de coisas, lugares e pessoas umas contra as outras); a nomeação (de coisas, lugares e pessoas enquanto reais); o espaço no mundo (ou seja, a ordem do espaço social por meio e ao redor da mídia); e, por fim, a imaginação de um mundo que se resulta de outras operações de poder midiático. Conforme eu argumentei, de todas essas maneiras fundamentais e interligadas, o poder midiático trabalha para se fortalecer, naturalizando o papel das instituições midiáticas na sociedade, e, assim, tornando o poder midiático um fenômeno muito difícil de analisar. Por meio desse modelo multinível, eu estava tentando me afastar do que percebia como sendo maneiras simplistas de pensar como o poder midiático funciona, por exemplo, a noção de "lógica midiática", introduzida nos anos 1970 e 1980 por David Altheide e Robert Snow (COULDRY, 2000, p. 18-19). Infelizmente, ninguém se utilizou desse modelo de poder midiático, e eu não o desenvolvi muito profundamente. Então, hoje, a pergunta segue sem respostas: qual é a melhor maneira de desvelar claramente o funcionamento do poder midiático, quando a mídia é tão fundamental na sociedade e seu funcionamento tão enraizado no nosso dia a dia?

No meu trabalho seguinte, tentei responder essa pergunta focando no que eu chamava de "rituais midiáticos". Maneiras concentradas nas quais as instituições midiáticas estavam envolvidas na reprodução de crenças da mídia por meio de formas sociais organizadas que eram separadas do fluxo normal da vida comum: formas como reality shows, talk shows e eventos midiáticos. No plano de fundo havia o meu interesse no papel da mídia na organização da sociedade e do espaço como um todo. Eu estava impressionado por um insight de Jean Baudrillard em 
um ensaio chamado Requiem for the media, no qual o autor afirma que os meios de comunicação eram muito mais do que mecanismos para a distribuição de conteúdo, eram formas de vida que "induzem uma relação social” (1981, p. 128). Conforme eu argumentei, compreender essas formas significa mais do que compreender os rituais midiáticos, eles próprios. Significa compreender a maneira de organizar a sociedade que torna possível algo como os rituais midiáticos. Chamei essa tese de "o mito do centro mediado", que defini no início do meu livro Media Rituals como "a crença, ou suposição, de que há um centro do mundo social e que, de alguma forma, a mídia é ‘porta-voz’ desse centro” (2003, p. 2) e as formas de organizar o mundo social também nessas mesmas bases.

Pela primeira vez nesse livro, explicitei meu interesse no conceito de ordem social. $\mathrm{Na}$ verdade, defendi a importância dessa questão, me unindo à posição do sociólogo francês Émile Durkheim contra os pós-estruturalistas e pós-modernistas que queriam abandonar a ideia de ordem social (2003, p. 5, 9-11). Entretanto, eu gostaria de ter trazido os insights de Durkheim sobre a ordem social de maneira crítica: o meu objetivo não era celebrar o papel da mídia na ordem social. Mas lembrem-se: eu estava escrevendo em um período no qual a diversidade midiática significava TV e rádio com diversos canais, uma mídia massificada florescente e apenas uma internet lenta que se podia acessar por meio de computadores de mesa e notebooks. O telefone celular existia no mundo separado da comunicação interpessoal. Naquele mundo - em 2003 - ainda fazia sentido, como fiz, trazer como suposição fundamental o que Durkheim fez no início do século XX. A suposição, como escrevi, de que "em alguns momentos específicos, vivemos explicitamente como seres sociais, como membros de um todo social compartilhado" (2003, p. 6). Para Durkheim, rituais são momentos nos quais entramos em contato com o que chamava de "a vida séria": os momentos nos quais Durkheim acreditava que nos uníamos enquanto sociedade, em conjunção com instituições sociais fundamentais. Mas a minha ênfase era sobre como essa experiência da "vida séria" foi sempre construída, 
construída pelas instituições midiáticas que se beneficiaram dessa crença, uma vez que ela cria a base da nossa atenção compartilhada à mídia. Eu estava oferecendo aqui uma alternativa à compreensão padrão marxista de poder social que argumentava ser melhor para compreender o poder social de maneira que "reconheça as pressões difundidas em direção à ordem nas sociedades mediadas” (2003, p. 12). Então, lá estava eu em 2003 falando sobre ordem social, um tema que se tornou ainda mais importante desde então, como iremos ver.

Ao desenvolver o conceito de rituais, eu enfatizei explicitamente os conceitos cognitivos do modelo de Durkheim sobre como as sociedades pareciam se manter unidas - seu interesse no papel do ritual no modo como o pensamento e o espaço eram organizados - em vez da ênfase alternativa dos aspectos emocionais do ritual. Hoje, em uma era de mídias sociais, eu colocaria a ênfase de maneira diferente. Uma escolha ainda mais importante tomada nesse período e cujo significado completo estava oculto no momento para mim, foi escolher a perspectiva do ritual como forma de pensar sobre a ordem social como um todo. Rituais são processos que oferecem acesso especial aos valores mais importantes do mundo social. Assim sendo, voltando às dimensões do poder midiático no modelo original, a abordagem significava enfatizar como os rituais enquadram certos aspectos do mundo, e categorizam ou ordenam determinadas coisas como sendo especiais: por exemplo, nos rituais religiosos, a distinção entre o sagrado e o profano, ou nos rituais midiáticos o enquadramento que demarca certas pessoas, coisas ou lugares de modo diferente do que ocorre com pessoas, coisas ou lugares meramente "normais". Entretanto, a ênfase no papel do ritual na ordem social significa prestar menos atenção a outras maneiras pelas quais a mídia pode contribuir para a ordem social, por exemplo, a simples nomeação de coisas enquanto reais (enquanto notícia), ou o processo que em 2000 eu chamei de "espaçamento", a organização do espaço de maneira a apoiar o mito do centro mediado. Talvez, como veremos, esses aspectos da mídia tenham se tornado mais importantes hoje. 
Naquele momento eu já tinha a intenção de ir além dos contextos limitados do ritual, trazendo o conceito de ritualização criado pela falecida Catherine Bell. Rituais, Bell dizia, são eventos relativamente raros, mas que dependem para a sua existência de processos do mundo social que desenvolvem as categorias apoiadas pelos rituais. Como eu costumava dizer, "a qualidade mais central da ritualização é o modo como ela organiza nossos movimentos ao redor do espaço e nos auxilia a vivenciar os recursos construídos do ambiente como sendo reais" (2003, p. 29). Nesse período, usei uma citação de Bell a qual só fui compreender completamente agora: "a construção orquestrada de poder e autoridade em ritual, [...] engaja o corpo social na objetificação de oposições e na implementação de esquemas que reproduzem efetivamente as divisões da ordem social" (1992, p. 215, grifos meus). Voltaremos a essa citação, porque ela tem uma nova relevância surpreendente na era dos algoritmos e do Big Data. Então, esse era o lugar onde estavam os meus pensamentos acerca das relações entre mídia e ordem social em 2003, antes que qualquer pessoa, que não fosse da área de engenharia de computação, tivesse alguma ideia a respeito das plataformas de mídia social.

\section{Desestabilizando a base do poder midiático?}

Quando voltei à teoria midiática alguns anos depois, o mundo já era outro. O acesso à internet rápida já estava disponível para uma grande quantidade de pessoas nos países onde eu pesquisava e o uso da internet foi se tornando cada vez mais integrado à vida normal. Plataformas de mídia social como o Facebook surgiram e cresceram muito rapidamente, ainda que os telefones celulares ainda não tivessem acesso à internet. Quais eram os desafios dessas mudanças, pensei, para compreender como a mídia contribui para a ordem social? Uma coisa já era clara: o mundo online não oferecia traduções simples de rituais midiáticos que eram normais na era pré-internet. Escrevi em 2007 um artigo que era um pouco cético sobre se uma forma de ritual midiático, a peregrinação, realmente existia no contexto online. Já que todo espaço online era o resultado de seu design de software, e a maioria desses espaços 
eram ligados a outros, que espaço haveria que poderia ser tão especial quanto espaço único no qual, por exemplo, um filme foi filmado ou um evento aconteceu? Quando lecionei meu curso sobre rituais midiáticos, eu dizia aos alunos que, embora os rituais midiáticos online ainda não estivessem devidamente comprovados, não havia dúvida de que o mundo online havia contribuído para a ritualização da mídia. Isso era muito claro, por exemplo, no papel da discussão nas mídias sociais sobre reality shows ou eventos midiáticos. Isso foi exatamente o que Bruno Campanella pesquisou em seu livro Os Olhos do Grande Irmão.

Mas as coisas seguiram mudando. Conforme o tempo online da sociedade foi aumentando, surgiram desafios para a minha compreensão do papel da mídia em relação à ordem social. Em 2017, o pesquisador americano Joseph Turow, em seu livro Niche Envy, argumentou que como resultado do crescimento do tempo online e os desenvolvimentos da indústria de marketing, os profissionais de marketing foram se tornando cada vez menos interessados em atingir os consumidores como parte do grande público (em um programa de TV ou um jornal, por exemplo), e muito mais interessados em monitorar consumidores individuais continuamente onde quer que estivessem e o que quer que estivessem fazendo online. Conforme especulei, será que o resultado poderia vir a ser uma mudança mais fundamental, uma desestabilização do próprio mito do centro mediado? Discuti essa possibilidade em um artigo, publicado em 2009, chamado “A mídia tem futuro?" (COULDRY, 2009). Mas eu concluí que, mesmo que os profissionais de marketing estivessem mudando seus interesses, como ainda estão mudando hoje, distanciando-se das narrativas de larga escala voltadas para o grande público, outras instituições - como o governo e a sociedade civil - ainda tinham interesse no que chamei de "espaço das aparências" da mídia. Caso contrário, sem a mídia, onde aconteceria a política, e sobre o que trataria a política? O resultado que sugeri em 2009 foi que o mito do centro mediado "é agora mais abertamente contestado e mais ativamente produzido que antes" (2009, p. 438). E eu acredito que essa afirmação ainda é de alguma forma verdadeira nos dias de hoje. 
Isso foi há 10 anos, e não há dúvidas de que eu estava certo em estar cético sobre a velocidade da mudança tecnológica. Dez anos depois, em 2019, eu estou palestrando em um congresso sobre televisão! Aqueles que em 2005 previram o desaparecimento da televisão há muito foram refutados. O motivo é claro se formos pensar na televisão não apenas como uma tecnologia de transmissão de conteúdo, mas, como nas palavras de Jean Baudrillard, uma forma de "moldar relações sociais. O tempo dispendido assistindo à televisão (e o modo como assistimos, se em um aparelho de TV ou no celular) até recentemente estava aumentando em muitos países, incluindo os EUA, o Reino Unido e a Alemanha. De qualquer forma, as empresas de televisão ainda dependem das mídias sociais como espaço de criação de lealdade aos programas de TV. Como eu disse há uns anos, a maioria das mídias tradicionais, como a televisão, estão em uma relação próxima com as plataformas de mídia social. A esta relação eu denominei como hélice dupla.

Você deve estar se perguntando se eu ainda acredito hoje que, como diz o ditado: "tudo mudou e nada mudou"! E sim, eu poderia ter continuado a argumentar que os rituais midiáticos continuam lentamente mudando as formas, que a ritualização se espalha pela internet, e que o mito do centro mediado continua, mesmo que a batalha por atenção com a mídia tradicional, principalmente a televisão, e a mídia social continue a se intensificar. Mas hoje eu não apresento mais o meu argumento exatamente desse modo, e a razão volta à questão fundamental sobre a ordem social - a natureza da ordem social - que eu disse no início que é a base no meu interesse pela mídia, o poder midiático, os rituais midiáticos em primeiro lugar. Então, o que mudou no papel da mídia na ordem social hoje em dia?

Mas antes de prosseguir, deixe-me contar uma história um pouco mais pessoal. Em 2012 e 2013 eu estava orientando um trabalho empírico no Goldsmiths College sobre práticas de storytelling digital em Salford, perto de Manchester. Originalmente, nós esperávamos pesquisar projetos para histórias em vídeo. Mas, conforme mergulhamos no trabalho de campo, duas coisas ficaram claras e mudaram o curso da 
minha pesquisa: primeiro, o impacto das plataformas de mídia social na vida social era tão profundo que era necessário retrabalhar completamente a teoria social. Em segundo lugar, mesmo com projetos que estava fazendo upload de histórias em vídeo para um website sem um componente de mídia social, uma nova dimensão foi se tornando importante: a crescente importância dos dados. Encontrei esses dados inicialmente na forma de análises (analytics) que mediam o desempenho do site, e que estavam transformando a maneira como muitas organizações entendiam quem eram e o que faziam no mundo. Mas desde então eu desenvolvi um interesse mais amplo sobre o papel dos dados no ordenamento do mundo social de forma geral. Em outras palavras, passei a me interessar por dataficação (datafication). Vamos discutir as mídias sociais e a dataficação a seguir.

\section{Os novos mundos das mídias sociais contínuas e da dataficação}

Primeiro, vamos falar sobre as mídias sociais.

Quando comecei a pensar sobre as plataformas de mídias sociais de maneira mais intensa e a observar como elas são descritas, comecei a notar que não só o mito do centro mediado continua a ser contestado, mas um novo mito acerca do papel da mídia na sociedade está crescendo. Trata-se de uma descrição do mundo centrada no tempo que dispendemos nas plataformas de mídias sociais. Em um artigo lançado em 2014, chamei a isso "o mito de nós" (COULDRY, 2014). Nesse estudo, tentei refletir sobre a transição dramática trazida pelo crescimento das mídias sociais. Antes das plataformas de mídias sociais, a vida social era localizada apenas parcialmente online e apenas para algumas pessoas que escreviam blogs, registravam comentários regularmente e participavam de espaços como jogos online e listas de discussão. Em 2012/2013, a vida social para uma grande parcela da população em muitos países começou a ser principalmente online, em plataformas digitais. Claramente, isso não era algo que os teóricos sociais pudessem ignorar. No 
entanto, as mídias sociais não assumiram a centralidade social da mesma forma que as instituições midiáticas tradicionais, porque a ênfase sempre é a de que as redes são os usuários, ou seja, as pessoas que, por exemplo, compõem o que o Facebook chama de "comunidade global". Frequentemente, em conversas informais, os usuários falam sobre os seus espaços online como lugares onde as pessoas que se conhecem se juntam. Há uma pressão tremenda em pensar esses ambientes como o espaço onde a socialização acontece, o que deve significar que as pessoas que se reúnem lá somos simplesmente "nós", todos os membros da sociedade.

Mas a ideia de "nós" - o "sujeito coletivo" das plataformas de mídias sociais - é tão construída e mítica quanto a ideia de que as instituições tradicionais de mídia são centrais socialmente. Plataformas são construções de softwares complexos que permitem certos tipos de interação e não outros. As plataformas têm muitos recursos que são, às vezes, perturbadores como, por exemplo, a habilidade de espalhar rumores de maneira rápida e ampla, recursos que criaram grandes preocupações no Brasil e em outros lugares. Mas o meu interesse hoje não é em relação às fake news, mas, sim, em questões mais gerais das teorias sociais a respeito de onde a vida social acontece e como nós imaginamos ser a vida social. Nos últimos dez anos, surgiu o mito da "coletividade natural", que chamo de "o mito de "nós" (2014, p. 855). Esse mito é completamente essencial para a legitimação e para a promessa comercial de muitas companhias tecnológicas, assim como o mito do centro mediado foi central - e ainda é, de alguma forma - para as instituições tradicionais de mídia. Pode ser que, sob a pressão de vários escândalos recentes, empresas como o Facebook reformulem a história contada sobre os espaços criados por eles, enfatizando, como vimos há três semanas, a criação de espaços de grupo criptografados, e não espaços individuais. Veremos. Mas as histórias das plataformas de mídias sociais acerca do seu papel na ordem social são muito importantes, seja qual for a forma que elas tomem. 
Assim como no mito do centro mediado, o mesmo ocorre com o mito do "nós": podemos analisar as linguagens que o sustentam - as histórias gerais sobre a necessidade de conexão que esses tipos de plataformas trazem, a forma como a plataforma categoriza um tipo de atividade e um tipo de uso em detrimento de outros, com algumas "experiências" sendo marcadas como mais especiais do que outras e um quadro geral sobre como o mundo social se encaixa nisso. Mas já não estamos no território do ritual aqui: de fato, quando os algoritmos do Google ou do Facebook tentam criar um senso de ritual ao lembrar-nos de aniversários ou trazendo imagens de certo tipo, eles normalmente fracassam, provavelmente porque os engenheiros do Google ou do Facebook não têm a compreensão dos processos reais de ritualização que fazem com que os rituais sejam possíveis! Mas isso não importa. O motivo pelo qual isso não importa é que torna as coisas realmente interessantes.

É neste momento que eu quero falar sobre o papel dos dados na ordem social explicitamente. Conforme eu mencionei, eu comecei a me interessar pelo papel dos dados na construção e reconstrução do mundo social - em outras palavras, os processos de dataficação. Isso aconteceu quando, em um trabalho de campo, eu descobri o quão importante era o processo de medição de dados para quase todo tipo de empresa. A análise de dados, por exemplo, em um site, envolve um processo de tradução: traduzir os valores originais de uma organização no mundo social mais amplo em medidas analíticas, e depois que a medição ocorre, o processo de medição deve ser convertido novamente em algo que faça sentido em termos de valores da organização. Esse é o processo que eu e minha equipe em Goldsmiths chamamos de "análise social real”. Ela tem como base algo fundamental que não tem relação com a televisão, mas, sim, com os computadores: conforme os computadores começaram a operar em sociedades contemporâneas, eles armazenaram registros de diversas coisas que os computadores fazem (eles monitoram a si mesmos, em outras palavras) e porque os computadores estão conectados, esses recursos podem estar disponíveis para outros computadores. Como um fato básico de como os computadores funcionam, é possível 
que eles monitorem a si mesmos e monitorem outros computadores. A partir desses dois fatos simples sobre como os computadores e a nossa infraestrutura atual de comunicação operam, nós temos a base para uma mudança extraordinária na ordem social contemporânea. A possibilidade de um rastreamento ou monitoramento contínuo de computadores por outros computadores. Algo que nós comumente conhecemos como vigilância.

Eu estive interessado na questão da vigilância por muito tempo porque, claramente, esse era um dos aspectos do crescimento dos reality shows no final dos anos 1990. Mas o crescimento da vigilância computadorizada não é apenas mais amplo, mas cria um fenômeno sem equivalência na era dos reality shows, que é a coleta de dados generalizada sobre o mundo por corporações de todos os tipos. E não apenas a coleta de dados, mas a tomada de decisões a partir desses dados, baseando-se apenas parcialmente na tomada de decisões feita por humanos, mas muito mais em processos automatizados de cálculo chamados algoritmos. Então aqui estava eu, em 2012, um sociólogo midiático, cujo foco principal era a televisão e os seus desdobramentos, quando comecei a me interessar pela coleta de dados. Descobri o trabalho excelente de Oscar Gandy (1993) que, no fim dos anos 1980, estava analisando a coleta de dados em larga escala por corporações de cartão de crédito e outras, insistindo que os dados são coletados por um motivo e que esse motivo era a discriminação econômica e social. Então, deixe-me lembrá-los da citação de Catherine Bell sobre ritualização enquanto processo que faz possível "a objetificação de oposições [ou seja, discriminações] e a implementação de esquemas que reproduzem efetivamente as divisões [ou seja, as hierarquias] da ordem social". Claramente, na era da dataficação, voltamos a algo similar a isso. Quais são, então, as implicações desse processo?

\section{Dataficação e a ordem social}

Nos últimos cinco anos, eu desenvolvi meu pensamento sobre plataformas e dados digitais - a era do Big Data - a partir dessas origens e elas 
me levaram para muito longe da questão da televisão. Primeiramente, no livro The Mediated Construction of Reality, escrito por Andreas Hepp (COULDRY; HEPP, 2016), eu trabalhei com a questão da teoria social no mundo digital, trazendo conceitos da fenomenologia clássica - o texto de Berger e Luckmann lançado nos anos 1960 sobre "a construção social da realidade” - mas atualizando-a para uma era na qual grande parte de nossas vidas se passa online, interagindo com pessoas que estão fisicamente distantes de nós. No Capítulo 7 desse livro, nós analisamos especificamente as implicações do processamento de dados para a construção social da realidade. E então, no meu novo livro, escrito com o pesquisador mexicano Ulises Mejías (COULDRY; MEJÍAS, 2019), eu foquei exclusivamente nas questões relativas aos dados e suas implicações na ordem e no poder social. Ao invés de focar nos detalhes desses dois livros, o que nos distanciaria do objetivo dessa conferência, eu gostaria de falar, na próxima parte da palestra, sobre duas coisas. Primeiro, gostaria de refletir sobre a natureza do que mudou nas relações entre mídia e ordem social. Depois, gostaria de considerar as implicações dessa transformação para as organizações midiáticas em si, incluindo as organizações midiáticas tradicionais como as empresas de televisão. Já que hoje eu não trabalho diretamente com a televisão, parte do que eu vou dizer será especulação, mas espero que isso traga uma base para a discussão.

Ninguém duvida que os rituais midiáticos ainda existam de alguma forma: eventos midiáticos, alguns reality shows, eventos esportivos, talk shows e assim por diante. E isso significa que, de alguma maneira, o centro mediado ainda está sendo construído. Se não estivesse, seria difícil entender por que grandes populações continuam a assistir à televisão, incluindo TV ao vivo. Sim, há sinais de mudança em longo prazo. Uma pesquisa recente feita pelo órgão regulador britânico Ofcom descobriu que a forma principal que as crianças britânicas assistem televisão atualmente não é no aparelho tradicional de televisão, nem mesmo em versões online de canais de TV, mas sim no YouTube, em laptops ou tablets. E, sem dúvida, algumas formas de ritualização estão surgindo 
através do YouTube. No entanto, as ligações entre o YouTube e o mito do centro mediado ainda estão por ser investigadas: talvez o YouTube seja o site, em um país como a Grã-Bretanha, com o declínio da audiência da televisão massificada pela juventude, por meio do qual eles buscam algo como um centro. Mas as dinâmicas são claramente muito diferentes daquelas das versões iniciais do centro mediado.

Talvez a pergunta sobre o destino do centro mediado não seja o ponto mais importante? Vamos voltar a olhar mais detidamente aquela citação de Catherine Bell que eu mencionei algumas vezes: "A construção orquestrada do poder e da autoridade em ritual [...] engaja o corpo social na objetificação de oposições e na implementação de esquemas que reproduzem efetivamente as divisões da ordem social" (1992, p. 215, grifo meu). Vamos pensar mais profundamente nessa citação - importante para a minha teoria original de rituais midiáticos e trazida por uma das pesquisadoras críticas mais importantes a respeito do ritual religioso na sociedade há um quarto de século - e no que essa frase nos diz, agora, em um novo contexto. Podemos chegar a isso ao questionar o que a citação supõe como ponto de partida? O que ela supõe é que a sociedade precisa da "construção orquestrada do poder e autoridade no ritual" para "engajar" atores sociais e a vida social na "objetificação de oposições e na implementação de esquemas que reproduzem efetivamente as divisões da ordem social"; o que significa que a sociedade precisa de rituais para a reprodução e o fortalecimento das categorias sociais, e que essas categorias são necessárias para construir hierarquias mais amplas e divisões sociais.

Mas essa visão sobre como a ordem social depende do ritual oferece hoje só parte da verdade. O motivo não é porque a análise do ritual não é útil (ainda é útil) ou que os rituais desapareceram (eles não desapareceram). O motivo é que, na sociedade, há agora novas forças gigantescas trabalhando para categorizar a vida social e a cada um de nós enquanto membros da sociedade. E que os meios dessas forças são as enormes quantidades de dados coletados no dia a dia, inclusive a partir das nossas ações em plataformas de mídias sociais. A questão do Big Data é muito 
mais ampla do que as plataformas de mídias sociais, mas para manter as coisas em foco, vamos continuar com as plataformas e suas práticas de coleta de dados que se tornaram bastante controversas nos últimos anos. Se nós formos relembrar o meu modelo de quase 20 anos atrás e suas cinco dimensões de poder midiático, podemos traduzir o que aconteceu com o Big Data e as mídias sociais em suas determinações: as dimensões de enquadramento, ordenamento, nomeação, espaçamento e imaginação. Podemos dizer que as plataformas de mídias sociais e as corporações que são donas delas adquiriram o poder de enquadrar o mundo social e, por meio disso, nomear o que acontece nele, além de categorizar tudo, ou seja, ordenar por meio de seus algoritmos. Nesse percurso, conforme nossas vidas foram cada vez mais sendo organizadas a partir do tempo que passamos nessas plataformas, o mundo social se dividiu em diferentes formas - um processo de espaçamento -, alterando, assim, como imaginamos o mundo social em longo prazo.

E, claro, não apenas os usuários comuns das plataformas sociais são afetados por essa mudança. Os dados de mídias sociais - e as categorizações que são baseadas neles - são usados generalizadamente por empregadores, universidades, partidos políticos, governos como recurso para gerenciar a população. E as próprias instituições midiáticas como, por exemplo, redes de transmissão como a BBC - estão cada vez mais medindo e aplicando novas formas de análise de seus próprios dados como medidas de desempenho e como forma de compreender os seus públicos e suas relações com os públicos do Reino Unido, Holanda, EUA e acredito que aqui do Brasil também.

Podemos descrever essa transformação por meio da dataficação de outra forma também. Por meio da dataficação - e mediante a incorporação resultante do rastreamento automatizado contínuo das nossas vidas sociais através dos nossos celulares e dos enormes recursos investidos atualmente no processamento de dados que esse rastreamento gera as instituições contemporâneas (incluindo o governo e as instituições midiáticas) estão mudando de dentro para fora. Jose Van Djick foi a primeira a perceber isso em seu livro The Culture of Connectivity quando 
escreveu que "por meio das mídias sociais, [...] os atos do discurso casual se tornaram inscrições formalizadas, as quais, uma vez incorporadas à grande economia de público amplo, assumem um valor diferenciado" (2013, p. 7). O resultado, argumenta, é a mudança da natureza do social em si. "O significado de 'social' [...] parece compreender tanto a conexão (humana) quanto a conectividade (automatizada)” (2013, p. 12). Vamos tentar compreender esse ponto de vista detidamente, já que ele representa uma transformação ao mesmo tempo profunda e sutil.

Até, digamos, 12 anos atrás, antes das plataformas de mídias sociais se tornarem parte comum da vida social, todas as teorias poderiam supor que o mundo social se ordenava a partir das coisas que cada um de nós faz como atores sociais: conectar, interpretar, comentar, criar sentido, concordar ou discordar uns dos outros. Aqui está uma versão típica dessa suposição em Berger e Luckmann, dois dos principais sociólogos da década de 1960, que diziam que "o dia-a-dia se apresenta como uma realidade interpretada pelos homens e subjetivamente significativa para eles enquanto mundo coerente [...] Um mundo que se origina em seus pensamentos e ações e é mantido enquanto real por esses" (BERGER; LUCKMANN, 1966, p. 33). Mas, agora, como exposto por Van Dijck, a própria ideia de conexão com outros seres humanos foi transformada pela conectividade, pelos objetivos das corporações comerciais que são donas das plataformas e que buscam garantir que nós estejamos conectados para que os dados sejam extraídos de nós e para que mais lucro seja criado. Eu iria além. No meu livro com Ulises Mejías, argumentamos que a ordem da vida social que surge hoje é produto não apenas do que os seres humanos fazem em conjunto, mas é moldada por novas ambições corporativas: como anexar ao capital cada ponto no tempo e espaço, reproduzir ou, podemos dizer, clonar relações sociais a fim de que essas anexações com o capital pareçam naturais e construir uma ordem social que capitaliza a vida humana sem limitações.

Essa transformação, eu diria, opera em um nível que não podemos atingir com nossas ferramentas normais de análise de mudança social - os conceitos de poder, em nível institucional; e identidade ou 
agência, em nível individual ou grupal. Essa é uma mudança na própria natureza do espaço social e nos tipos de relações que podem caracterizar o espaço social. Uma verdadeira mudança na natureza da ordem social. Mas, se isso for correto, então a ordem social não pode mais ser compreendida exclusivamente por meio da abordagem de Émile Durkheim, que estava preocupado com como os laços sociais são formados pelos seres humanos. Precisamos, desde o início, olhar o papel das corporações (e dos governos que trabalham com as corporações) para construir o próprio tecido social, o espaço social. A fim de fazer isso, precisamos nos basear em outro teórico social, ou melhor, um antigo teórico social cujo trabalho nos anos 1970 e 1980 foi completamente esquecido - quero dizer, o sociólogo alemão Norbert Elias. O que é particularmente útil é a maneira que Elias tem de pensar sobre a complexidade e a ordem social. A sua ideia é a de que a complexidade da vida social emerge das interconexões entre os seres humanos, dos padrões de interação que ele chama de "figurações". Figurações - um novo conceito para pensar a respeito da ordem social, que foi discutido em meu último livro (COULDRY; HEPP, 2016).

Figurações, para Elias, são "processos de entrelaçamento social” que têm um "tipo especial de ordem" que "se inicia [...] a partir das conexões, relacionamentos e trabalha [...] a partir disso, com os elementos envolvidos neles" (ELIAS, 1978, p. 116). Seu exemplo mais simples era o de um jogo de cartas ou de futebol ou um baile onde todos interpretam seu papel em relação às outras pessoas jogando. Como ele diz, “o comportamento de muitas pessoas em separado se entrelaça para formar estruturas entrelaçadas" (1978, p. 132, grifo meu). Na abordagem de Elias para a ordem social, em contraste com a abordagem de Durkheim, duas coisas são muito importantes. Primeiro, ele fala sobre o papel que as estruturas materiais têm - se formos aplicar isso aos dias de hoje, isso significa softwares, códigos de computador, servidores para armazenamento de dados, a nuvem. Em segundo lugar, ele insiste em pensar sobre as consequências dessa infraestrutura material, da tecnologia, do ponto de vista dos seres humanos emaranhados nessa infraestrutura. 
Elias pontuou eloquentemente esse argumento no fim de seu último livro: "as pessoas parecem esquecer deliberadamente que os desenvolvimentos sociais têm a ver com as mudanças da interdependência humana [...] Se não houver nenhuma consideração pelo que acontece com as pessoas no percurso da mudança social - mudança nas figurações compostas pelas pessoas - então qualquer esforço científico deve muito bem ser poupado" (ELIAS, 1978, p. 172).

Atualmente, há muitas preocupações sobre o papel das plataformas de mídia social na política, no governo, na família, na vida das crianças... Essas preocupações são importantes, e eu sei que são intensas no Brasil, por exemplo, quando falamos de WhatsApp. Mas muitos desses debates focam no que, por exemplo, o Facebook está fazendo de errado. Para mim, essa não é a questão mais importante. Vamos supor por um momento que o Facebook corrija todos os seus erros e gerencie suas plataformas de uma maneira muito melhor. Ainda haveria um problema mais profundo, que é um problema no qual todos nós estamos envolvidos - o problema da nova forma que a ordem social está sendo construída atualmente, e sendo reconstruída para interesses corporativos. Isso é algo que todos nós, com o nosso uso das plataformas de mídias sociais e muitas outras atividades, estamos contribuindo. A questão mais importante levantada hoje pelas nossas relações com as plataformas sociais e com muitas outras infraestruturas de coleta de dados é a natureza mutante da ordem social. Por exemplo, deixe-me mencionar os debates acalorados hoje nos EUA sobre as consequências da coleta de dados automatizada nas vidas dos pobres, que, nos EUA, desproporcionalmente significa as vidas dos negros. O artigo da pesquisadora de direito Patricia Williams no The Nation falou sobre isso há duas semanas, quando ela disse que "muitos de nós nos aprisionamos à tecnologia por escolha própria - os smart watches que usamos no pulso, o rastreamento de GPS nos nossos celulares, os apps de localização de carro, as falas de Siri. Elas não são percebidas enquanto ferramentas disciplinares; ao invés disso, elas são vendidas como formas de se conectar”. Ainda assim, ela sugere, 
é o que elas são: ferramentas disciplinares da ordem social operando por meio de processos de dataficação.

O exemplo mais dramático dessa nova visão de ordem social por meio da conexão, por meio da dataficação, vem da China. Na China, existem as plataformas digitais mais integradas socialmente: na verdade, as "superplataformas" como o Alibaba e o Tencent que combinam mídias sociais (algo como Facebook, Twitter e WhatsApp) com sites de e-commerce (como a Amazon) e com sites de finanças pessoais. Ao contrário do Ocidente, nenhuma dessas plataformas é criptografada e o governo tem uma estreita relação com os donos dessas plataformas. $\mathrm{O}$ governo ajudou no financiamento para a construção dessas plataformas. Vocês já devem ter ouvido falar do "Sistema de crédito social" da China, que o governo chinês planeja tornar operacional até 2020 e que irá criar uma pontuação para cada cidadão. Dependendo dos dados coletados a respeito de cada um online, ao indivíduo será atribuída uma pontuação em responsabilidade social. Em um importante documento de política descrevendo esse novo sistema, o governo chinês utilizou uma expressão interessante para descrever o que isso significa: "uma melhoria de mercado de ordem social e econômica” (Política do Sistema de Crédito Social Chinês, 2014). E, assim, voltamos à questão da ordem social, dessa vez não mais como um conceito teórico, mas com uma visão de um governo, um plano prático para gestão de uma sociedade. Uma visão que, até para os EUA, Patricia Collins chama de "uma prática cívica nada menos do que totalitária”.

\section{Conclusões}

Ao concluir a minha fala, eu gostaria de unir essas reflexões sobre a minha própria jornada intelectual a respeito de como eu troquei a análise do papel da televisão na reprodução da ordem social pelo estudo dos processos de dataficação, e perguntar-me o que, talvez de maneira surpreendente, isso pode dizer a respeito da importância da televisão nos dias de hoje. E, embora eu tenha discutido sobre dados nos últimos minutos, e não sobre televisão, há uma série de implicações importantes 
para a televisão que eu gostaria de dividir com vocês. Essas implicações aparecem mais em forma de questões, já que elas não são problemas que eu posso solucionar hoje, mas, sim, perguntas para pesquisas futuras.

Primeiro, precisamos entender até que ponto a natureza das próprias instituições de mídia, incluindo a televisão, está sendo alterada pela dataficação. Assim como mencionei anteriormente, há mudanças em andamento na forma como as instituições de mídia se medem e são avaliadas por quem as financia. Isso está profundamente relacionado a mudanças que ocorrem, de forma independente, nas indústrias de publicidade, onde há cada vez mais investimento em análise de dados e menos na produção criativa: o que, afinal, acontece a longo prazo com a produção de notícias quando os publicitários não estão mais interessados em subsidiá-la através de seus anúncios, em formas de mídia para a audiência geral, como os boletins e jornais? E o que acontece nas indústrias midiáticas como um todo quando a publicidade se torna uma questão de microalvos detalhados e de gestão de dados, e não mais de campanhas publicitárias em nível nacional? Como, na era da dataficação, as instituições midiáticas representam o seu valor na sociedade? Quais serão as implicações para a sociedade quando a instituição midiática paradigmática se torna, globalmente, a Netflix ao invés vez da BBC? Essas são questões de muito longo prazo.

Além disso, há a questão sobre como compreendemos os novos tipos de instituições quasi-midiáticas que nós normalmente chamamos de plataformas. Como é bem conhecido, o Facebook nunca planejou ser uma empresa de mídia e passou muitos anos negando que deveria ter a responsabilidade de uma. Mas está sob pressão esmagadora para assumir responsabilidades pelos conteúdos que circulam em suas plataformas. Ainda assim, o Facebook não é uma instituição conduzida pelos valores profissionais das instituições midiáticas ou pelas habilidades dos profissionais de mídia. É uma empresa que media o espaço para interações sociais e, a partir disso, busca extrair valor no fluxo da atividade social. Esse é um objetivo corporativo que está diretamente 
em tensão com a venda de conteúdos de mídia que as pessoas desejem ler e interpretar.

Existe, então, por meio da intensificação dos processos de coleta de dados, um risco de esvaziamento do sentido nas instituições midiáticas em longo prazo? Em caso afirmativo, qual seriam as implicações para outras instituições da modernidade, particularmente, as instituições democráticas? Essa é a crise de hoje e ela está ligada às ameaças crescentes à legitimidade das plataformas de mídia social que estão assumindo alguns dos papéis das instituições midiáticas quando elas não têm os recursos para fazê-lo. E se a confiança em todas as notícias, mesmo as notícias produzidas profissionalmente, caírem à medida que a circulação de informações pelas plataformas se torna cada vez menos segura, mais imprevisível e mais arriscada?

Isso levanta um terceiro tipo de pergunta que é a respeito do tipo de respostas imaginativas a essas transformações que as sociedades podem esperar - ou talvez precisar - das instituições midiáticas. Em um mundo cada vez mais moldado por cálculos ocultos automatizados e pela discriminação, com certeza haverá um papel e uma necessidade ainda maior para as produções imaginativas das indústrias midiáticas, como intérpretes das mudanças que estão ocorrendo. Talvez, como locais de resistência imaginativa para a nova corporativização do mundo social que acabei de descrever.

Onde isso deixa o estudo das instituições de televisão e mídia hoje em dia? Vou resumir o que eu acredito que tenhamos aprendido com as minhas reflexões a respeito do meu pensamento sobre a relação da mídia com a ordem social nos últimos 20 anos. Primeiro, que precisamos reconhecer o novo papel (paradoxal e altamente conflituoso) desempenhado pelas instituições midiáticas em um mundo de contínuas conexões computadorizadas e da própria reconstrução corporativa do social. Precisamos de instituições midiáticas - e de seus recursos imaginativos - hoje, mais do que nunca, para trazer visões de mundos sociais que são mais do que extração automatizada de dados. Em segundo lugar, quando a camada social está sendo transformada por uma nova 
visão de ordem social, nós não podemos, enquanto estudantes ou pesquisadores, pensar no papel da mídia na sociedade sem a teoria social. Porque as sociedades que habitamos hoje não são sociedades da mesma maneira que as sociedades de quinze, ou, até mesmo, dez anos atrás. São tipos diferentes de ordens, regidos por diferentes tipos de poder e nós precisamos da teoria para nos auxiliar a entender qual é essa diferença.

Por fim, a teoria social que precisamos para entender esse tipo diferente de sociedade e de ordem social deve ser crítica: deve reconhecer o papel crescente das corporações - e os governos que trabalham lado a lado com essas corporações - reconstruindo um mundo social por meio de vigilância, para o lucro, com o objetivo de construir um novo tipo de ordem social que está em tensão profunda com a própria ideia de democracia. Esse mundo - nosso mundo emergente em muitos países como Reino Unido e EUA, Alemanha e Holanda, Brasil e China - é um mundo onde, ao contrário de qualquer previsão, as instituições midiáticas tradicionais ainda sobrevivem. Mas elas encaram desafios radicalmente novos e têm uma nova e estranha responsabilidade de nos auxiliar, enquanto cidadãos, a imaginar maneiras de evitar um futuro que seja completamente anexado ao capital sem nenhuma alternativa. Minha última pergunta é: seria o poder imaginativo da mídia um dos poucos recursos que restaram que, se voltado na direção certa, poderá nos ajudar a imaginar algo diferente de uma sociedade gerida exclusivamente pela força e pela força dos dados? Eu acredito que sim e é de responsabilidade das universidades e dos intelectuais críticos manter essa esperança viva.

\section{Referências}

ALTHEIDE, D.; SNOW, R. Media Logic. Beverly Hills: Sage, 1979.

BAUDRILLARD, J. Requiem for the Media. In: For a Critique of the Political Economy of the Sign. St Louis: Telos Press, 1981. 
BELL, C. Ritual Theory, Ritual Practice. New York: Oxford University Press, 1992. BERGER, P.; LUCKMANN, T. The Social Construction of Reality. Harmondsworth: Penguin, 1966.

CAMPANELLA, B. Os Olhos do Grande Irmão: Uma Etnografia dos Fãs do Big Brother Brasil. Porto Alegre: Editora Sulina, 2012.

COULDRY, N. The Place of Media Power: Pilgrims and Witnesses of the Media Age. London: Routledge, 2000.

Media Rituals: A Critical Approach. London: Routledge, 2003.

Pilgrimage in MediaSpace: Continuities and Transformations. Ethnofoor, v. XX, n. 1, p. 63-74, 2007.

Does "the Media" have a Future? European Journal of Communication, v. 24 , n. 4, p. $437-450,2009$.

The Myth of Us: Digital Networks, Political Change and the Production of Collectivity. Information Communication and Society, v. 18, n. 6, p. 608-626, 2014. COULDRY, N.; HEPP, A. The Mediated Construction of Reality. Cambridge: Polity, 2016.

COULDRY, N.; MEJÍAS, U. The Costs of Connection. Stanford: Stanford University Press, 2019.

DAYAN, D.; KATZ, E. Media Events. Cambridge, MA.: Harvard University Press, 1992. ELIAS, N. What is Sociology? London: Hutchinson, 1978.

GANDY, O. The Panoptic Sort. Boulder, CO: Westview Press, 1993.

MARTÍN-BARBERO, J. Communication, Culture and Hegemony. London: Sage, 1993. MELUCCI, A. Challenging Codes. Cambridge: Cambridge University Press, 1996. TUROW, J. Niche Envy. New Haven: Yale University Press, 2007.

VAN DIJCK, J. The Culture of Connectivity. Oxford: Oxford University Press, 2013.

\section{Sobre 0 autor}

Nick Couldry - Professor de Mídia, Comunicação e Teoria Social da London School of Economics and Political Science.

Data de submissão: 20/05/2019

Data de aceite: 13/09/2019 